L U N I VER S I T Y OF CALIF O R N IA

Designs for

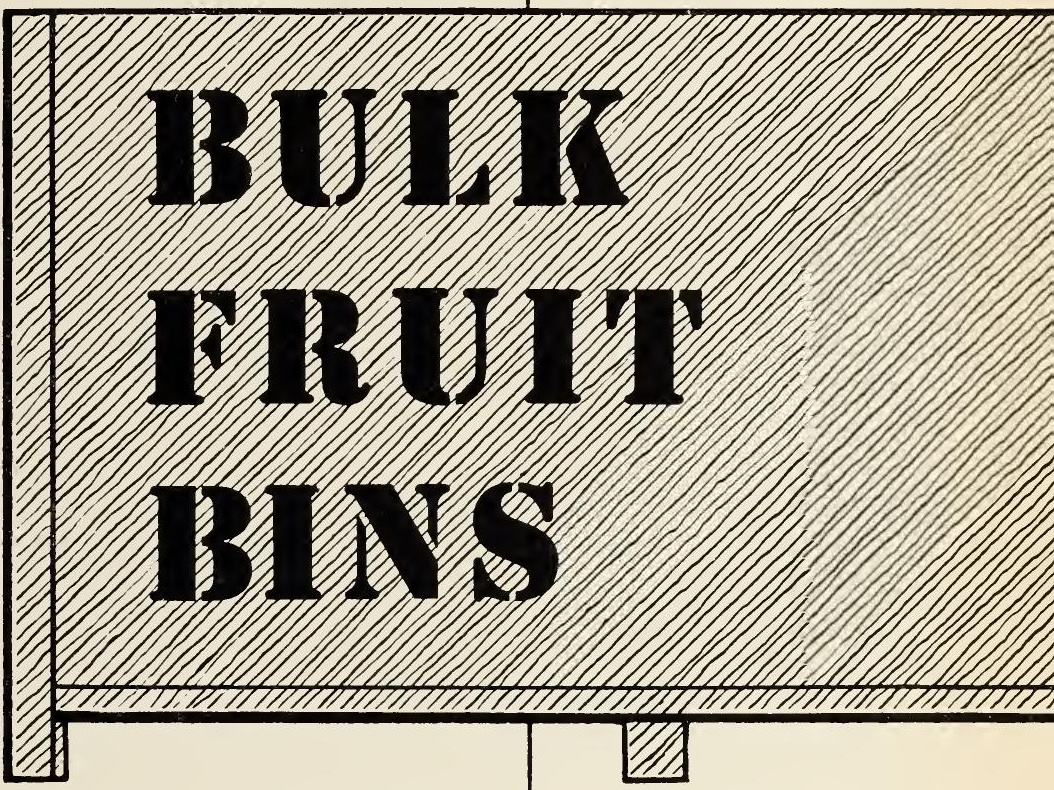

MICHAEL O'BRIEN

CALIFORNIA AGRICULTURAL Experiment Station Extension Service 


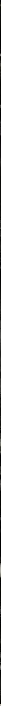

Handling bulk bins of fruit in the orchard with a tractor-mounted fork lift reduces time and labor.

Bulk bins for fruit harvesting and handling are replacing conventional lug boxes in California's deciduous-fruit packing industry. The use of bins has increased from 13,000 in 1958 to approximately 100,000 for the 1960 season. Clingstone peaches, pears, prunes, and apples have proved well adapted to handling in bins, as have some vegetables. More fruits and vegetables are expected to prove adaptable in the future.

Bulk handling is an important factor in the mechanization of the fruit and vegetable harvest. This circular reports the results of research conducted by the University of California Agricultural Experiment Station in coöperation with agricultural commodity groups. The object of this continuing research is to find means of reducing labor and costs without sacrificing quality.

\section{THE AUTHOR:}

Michael O'Brien is Lecturer in Agricultural Engineering and Associate Specialist in the Experiment Station, Davis. 


\section{Reduces costs for containers ...}

Containers for 1 ton of fruit in lug boxes on pallets cost approximately $\$ 56$. For 1 ton of fruit in two bins, the cost is approximately $\$ 28$.

\section{Saves labor ...}

Field distributing, collecting, and stacking of boxes by hand labor are eliminated when bins are used and handled with tractor-mounted fork lifts. In some operations, standard bins are filled on trailers in the field; in others, gondolas on trailers are used. Most growers, however, have substituted bins for boxes, and handle them in the field with fork lifts.

\section{Reduces storage space require- ments ...}

Three pallets 68 inches tall will stack 204 inches high, and contain 5,280 pounds of fruit. Seven bins 281/4 inches tall, occupying similar floor space, will stack 198 inches high and contain 7,000 pounds of fruit. This is an increase in capacity of 33 per cent.

\section{Cuts transportation costs ...}

One ton of fruit in boxes on pallets weighs 2,550 pounds; the same quantity in bins weighs 2,260 pounds. With a $\$ 6$ per ton hauling charge, this amounts to a saving of 87 cents per ton of fruit, or 43 cents per bin per trip.

\section{FRUIT INJURY}

Prevention of damage to fruit is of first concern in bin construction. Fruit injury may result from rough sides on the bin, contour of the bin bottom, and incorrect depth of bin. (Dropping fruit instead of placing it carefully in the bin during filling will also cause damage, but this is not the result of bin construction, and should be prevented by good management practices.)

Fruit abrasion on rough sides and on cracks in the sides may be eliminated by using sanded plywood or similar smooth material.

When the bin is filled to a reasonable depth, the fruit suffers only minor damage at the bottom of the bin, caused by the edges of the bottom boards. Easing the edges to a 20-degree angle will practically eliminate such damage. (The face of a 20-degree angle is a tangent to 1.4inch radius fruit.)

Early studies resulted in standardiza- tion of the base size of bins at 47 by 47 inches. Studies were conducted in 1959 to determine suitable depths.

Tests were made on bins $16,24,32$, and 40 inches deep, to determine the effect of depth on fruit damage during transportation of cling peaches. Test bins were vibrated at 13.6 cycles per second for 10 minutes at an amplitude sufficient to produce an acceleration of $0.24 \mathrm{~g}$ (acceleration of gravity) at the bottom of the bin. These vibration characteristics are within the range measured on trucks hauling fruit. Resulting damage to fruit at various depths was as follows:

\begin{tabular}{cccc} 
& \multicolumn{2}{c}{$\begin{array}{c}\text { Acceleration: } \\
\text { Depth of Bin }\end{array}$} & $\begin{array}{c}\text { Ratio of } \\
\text { Bottom }\end{array}$ \\
inches & $g$ & $g$ & Top \\
16 & 0.24 & 0.76 & 1.37 \\
24 & 0.24 & 1.00 & 1.00 \\
32 & 0.24 & 1.28 & 1.17 \\
40 & 0.24 & 1.08 & 1.28
\end{tabular}


The figures show that the least damage occurred in the 24-inch bins, although fruit at the top of these bins received higher accelerations than did that in the 16-inch bins. More damage occurred in the 40 -inch bins than in the 32 -inch, even

\section{FACTORS AFFECTING BIN DESIGN}

Bin design is influenced by space requirements, materials, cost, desired life, and means of handling. Other factors include type of pallet needed, type of sides, weight limitations, venting for precooling and storage, and susceptibility of fruit to injury.

About 15,000 bins were checked during the 1959 season to determine factors affecting design.

\section{Base size}

Bins 47 inches square are most efficient from the standpoint of materials and storage space required. They fit on transport trucks with adequate clearance, and provide a balanced package for handling.

\section{Depth}

As the table (p. 3 ) shows, fruit damage was least in bins 24 inches deep. Two full, 24-inch bins will hold 1 ton of fruit and have a gross weight of approximately 2,260 pounds. This will yield a gross weight of 22,600 pounds on a 20 -foot trailer loaded two bins high. To stay within highway weight limitations, a total fruit depth of 48 inches (two 24inch bins) can be accommodated. (It is convenient that this division coincides with results of tests showing minimum damage with this depth of bin.) The 24inch bins are good for most fruits and some vegetables. If bins are also to be used for "fluffy" or "light" vegetables, however, it may be well to have them somewhat deeper. If a deeper bin is desired, the design shown on page 8 may be modified by extending the diagonally cut $4 \times 4$-inch corner posts and attaching though accelerations at the top of the 32 inch bins were higher. One explanation for this is that a loop occurs between two vibration nodes near the 32-inch depth. Without exception, the damage to fruit was in the top layers in each of the bins.

$1 \times 6$-inch, select grade, surfaced boards. This adds $51 / 2$ inches to the depth, and the boards may be easily replaced.

\section{Volume}

The net volume of bins is important. Two bins used commercially during the 1959 harvest season were compared-one with $5 / 8$-inch plywood sides and an inside depth of 24 inches, the other with sides set in $1 \frac{1 / 2}{2}$ inches and an inside depth of 27 inches. Net volume of the bins was 29.1 cubic feet and 30.2 cubic feet, respectively. The 27 -inch depth provided a capacity for only 41 pounds more fruit than did the 24-inch depth.

\section{Materials}

Numerous combinations of materials can be used in bin construction. The important requirements are strength and rigidity. With plywood, the face grain should run parallel with the span. Stiffness varies markedly with thickness and direction of face grain (see graph I). Metal reinforcing conserves space and presents a wear-resistant surface. "Construction-and-better" grade lumber (formerly number 1 grade) has proved adequate for bin bottoms if the boards do not have knots.

\section{Cost}

When bins are well designed, cost is in direct proportion to the weight and quality of material used. About $\$ 14$ per bin, as previously quoted, is not out of line in view of the costs of the lugs and pallets the bin replaces. Some original costs do not include assembly. With good assembly-line manufacturing procedures, the 


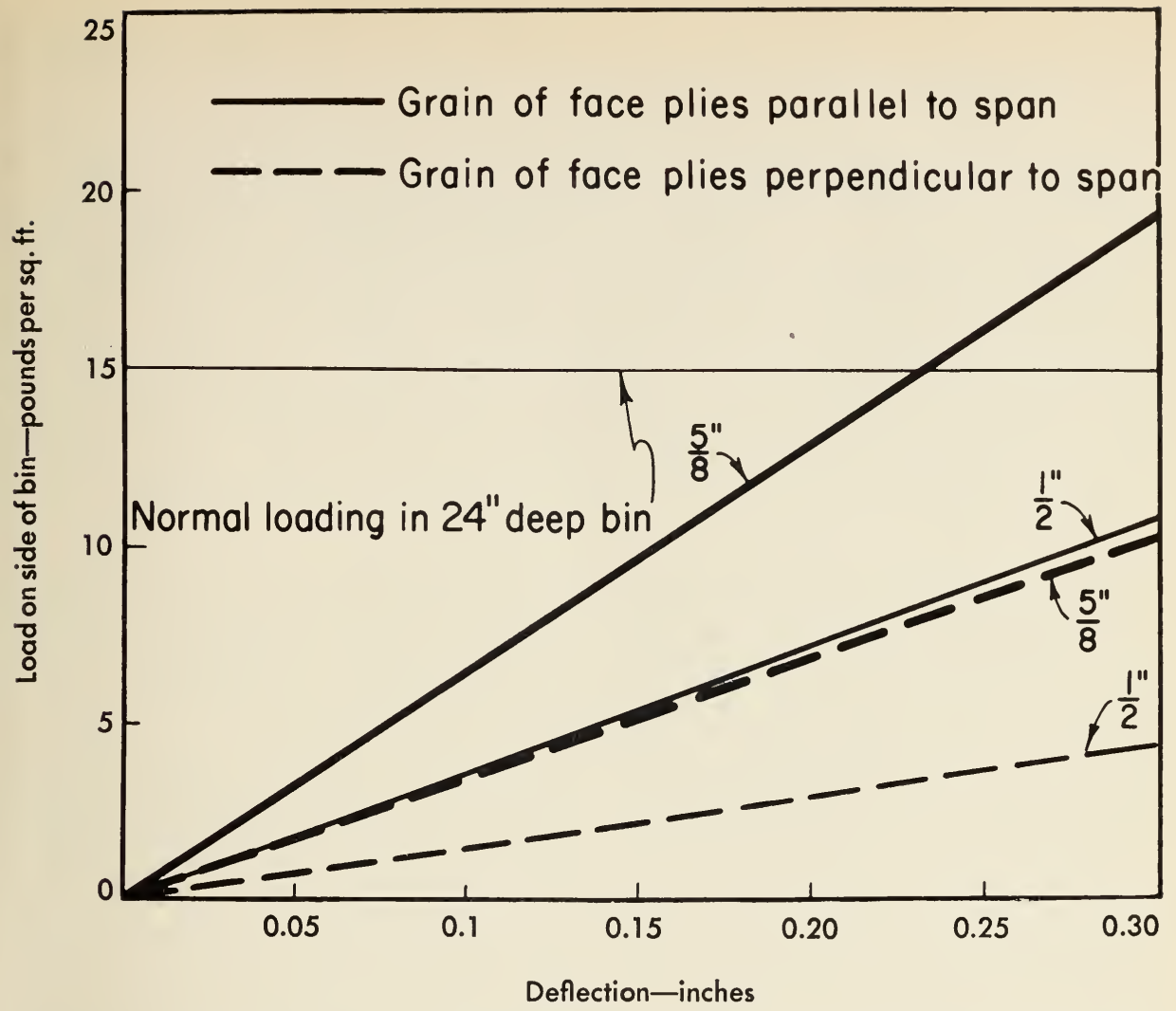

Graph 1. Face grain of plywood should parallel the span. Above comparison, for $1 / 2$-inch plywood, shows 2.5 times as much deflection for perpendicular grain as for parallel. The corresponding figure for $5 \%$-inch plywood is 2.0 .

labor costs of making different bins should be relatively close. Putting additional money into improved materials should result in a corresponding additional value in length of life, less fruit damage, less repairing, and fewer operating problems due to failure, and thus establish lower operational costs.

\section{Life}

No information is available on which to base an estimate of bin life. In 1959, of 15,000 bins checked, 576 were out of use because of damage (table 1). Of these, 432 could be repaired economically. Less than 1 per cent of all bins was a total loss although a far greater percentage will be damaged beyond repair with each succeeding year of use.

\section{Handling and pallet}

Bins with pallet bottoms are well adapted to conveyor-line and fork-lift handling. Two-way entry pallets under bins are adequate; four-way entry pallets were not found necessary in the orchards. Pallet skids need not have boards attached to the bottom; in fact, these boards were found to do more harm than good since they carried dirt from the orchard and spilled it on fruit in the bottom bins during transport. These boards are also troublesome because they are easily broken by fork-lift prongs. Bins with skids 3 inches wide by $31 / 2$ inches deep proved efficient in handling. Four-inchwide skids apparently did not improve the bins, and a $2 \times 4$-inch center skid was too easily knocked off by fork-lift prongs 
Table 1-Analysis :

\begin{tabular}{|c|c|c|c|c|c|c|}
\hline \multicolumn{2}{|c|}{ Bins } & \multicolumn{5}{|c|}{ Types of failure } \\
\hline \multirow{2}{*}{ Type } & \multirow{2}{*}{ Number } & \multicolumn{2}{|c|}{ Sides } & \multicolumn{2}{|c|}{ Reinforcing, side or top } & Corn. $x$ \\
\hline & & Number & $\begin{array}{l}\text { Per cent of } \\
\text { total bins }\end{array}$ & Number & $\begin{array}{l}\text { Per cent of } \\
\text { total bins }\end{array}$ & Number \\
\hline$A^{*}$. & 7,998 & 63 & 0.79 & 105 & 1.31 & 34 \\
\hline $\mathbf{B}^{*}$. & 5,016 & 41 & 0.82 & 69 & 1.38 & 86 \\
\hline $\mathbf{C} \dagger$. & 2,007 & 2 & 0.099 & 0 & 0.00 & 19 \\
\hline Total or average & 15,021 & 106 & 0.71 & 174 & 1.16 & 139 \\
\hline
\end{tabular}

* First year of use.

+ Second year of use.

because nailing was too near the neutral axis. A significant proportion of the damaged bins had bottom boards pushed off (table 1) because they did not extend under the bin sides. When bins are handled two-high, the weight of the top bin is supported by the sides of the bottom bin which, in turn, are supported by the bottom boards of the bin that rests on the fork-lift prongs. To solve this problem, the boards of the pallet should extend under the sides of the bin.

\section{Stacking}

Bins with corner posts stack more easily and with less danger of falling over than do bins lacking corner posts. A top corner surface should have a minimum of 2 inches each way for ease of stacking and for stability. Bins without corner posts should have sides strong enough to support 1,200 pounds for each bin that may be stacked above them in storage. The sides of some bins failed during storage in the 1959 season because they could not support the weight.

\section{Weight}

One ton of fruit can be handled in two 130-pound plywood bins, with a gross weight of 2,260 pounds; its equivalent in boxes on pallets will have a gross weight of 2,550 pounds. Thus, fruit handled in bins has a container tare of 13 per cent, as compared with 26 per cent for lug boxes on pallets. If the cost of hauling is $\$ 6$ per ton, the saving is 87 cents per ton, or 43 cents per trip per bin.

\section{Cooling and storage}

Studies on hydrocooling and storing of fruit indicate that bins should have solid sides with openings in the bottom for air or water drainage. The solid sides provide a flue effect that contributes to uniform cooling or warming of the fruit. One hundred square inches of open space were found to be optimum for ventilation. The vented bottom permits movement of air or water into and out of the bin during cooling or warming, and facilitates cleaning.

The half-cooling time of fruit hydrocooled in bins was significantly lower when openings in the bottoms of the bins were sufficiently restrictive that water entered faster than it escaped, until the bin was nearly full. When peaches were immersed in moving water, a lower halfcooling time was required than when an equal amount of water was showered over the fruit. Graph II shows results when a two-stage hydrocooler was used.

Tests on air cooling in 24-inch bins showed no significant difference between bins with slotted sides and those with solid sides.

The bins with a 24-inch depth of fruit and 100 square inches of open space in the bottom, and having 5 gallons of water 


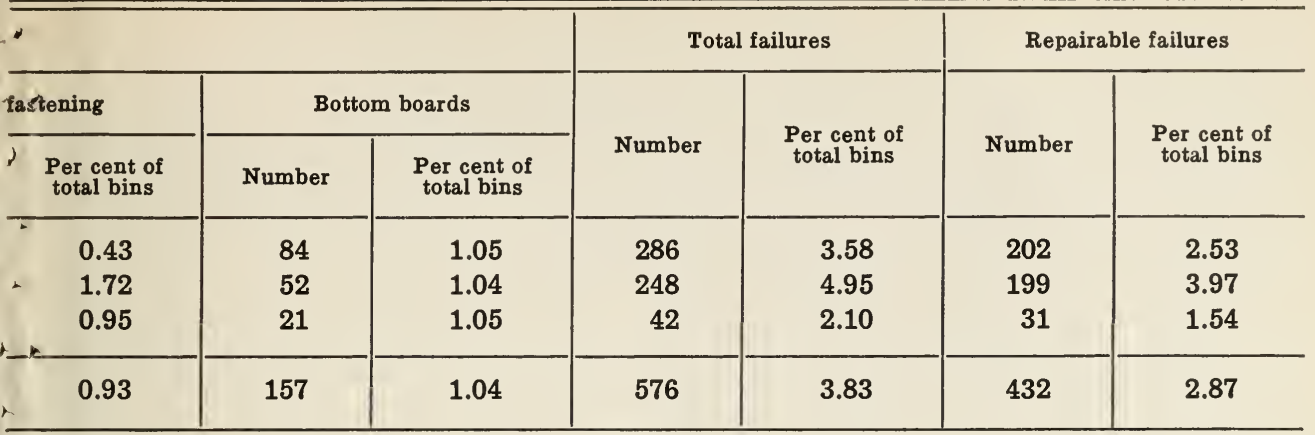

per cubic foot of peaches flowing through freely, were compared with bins of equal size that had 10 square inches of open space in the bottom permitting a flow of 3 gallons per minute per cubic foot of peaches, with a hydrostatic head equal to the depth of the bin. The bins that filled with water had a half-cooling time of 8 minutes as compared with 10 minutes for those that did not fill with water.

Although 10 square inches of open space in the bin bottom are adequate for hydrocooling, it must be remembered that 100 square inches of opening are desirable for room storage, air cooling, and cleaning.

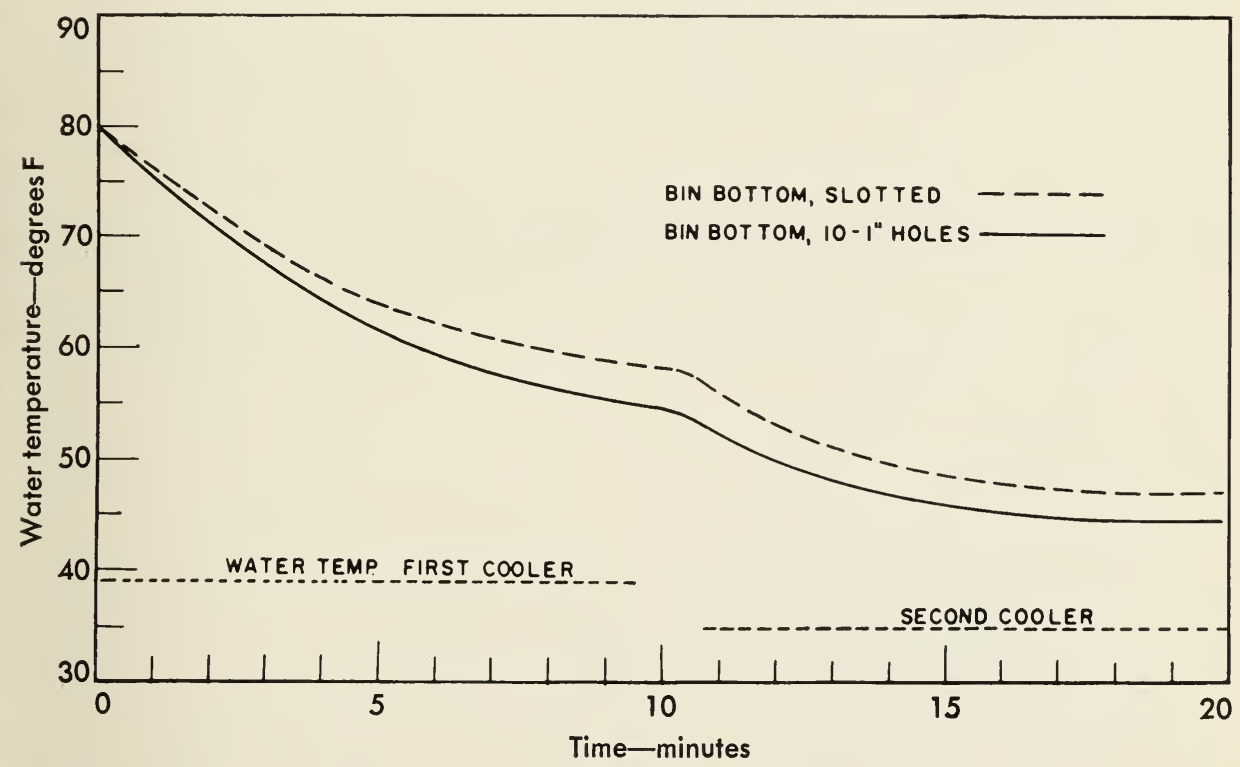

Graph II. Cooling times for peaches in a two-stage hydrocooler. 


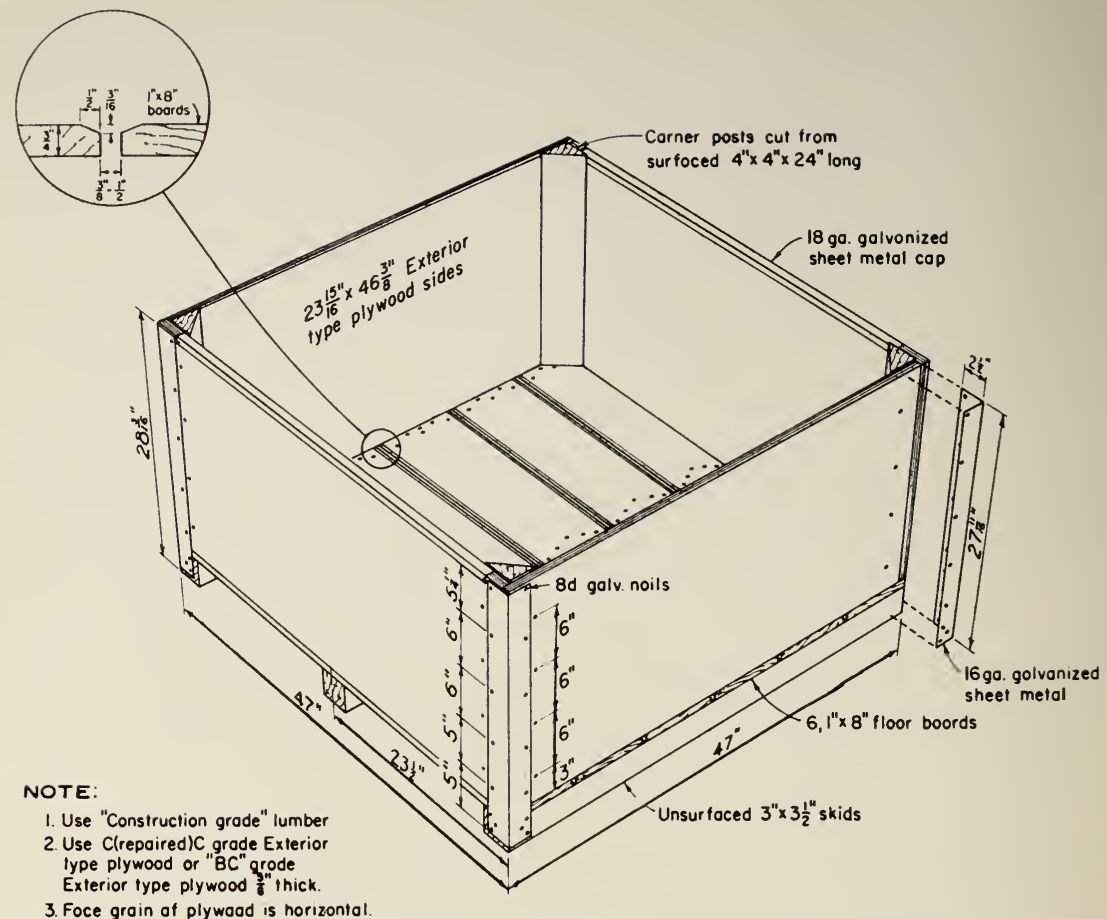

PERSPECTIVE

Detailed plan of reinforced plywood fruit bin. This bin is designed so that action of all normal forces places nailed fastenings in shear and/or compression. This minimizes the common problem of failure due to loosening of nails or bolts.

\section{RECOMMENDATIONS}

Specific recommendations and plans presented here incorporate features found desirable as a result of the investigation. Bin manufacturers or purchasers may emphasize specific features or needs applicable to their own operations. The following recommendations for bin design are based on research conducted during the 1957, 1958, and 1959 seasons.

Use 47-inch-square bins for efficiency in handling and storage.
Use 24-inch inside depth of bin (281/4 inches over-all) for minimum transport damage to fruit and for stacking seven. high in 17-foot storage.

Use two-way entry pallets on bins rather than four-way ones, with $3 \times 3 \frac{1}{2}$. inch skids for pallets. Do not use boards on the bottom of the skids.

Use $5 / 8$-inch, exterior grade plywood sides with galvanized sheet-metal corner bracing for maximum usable space, 


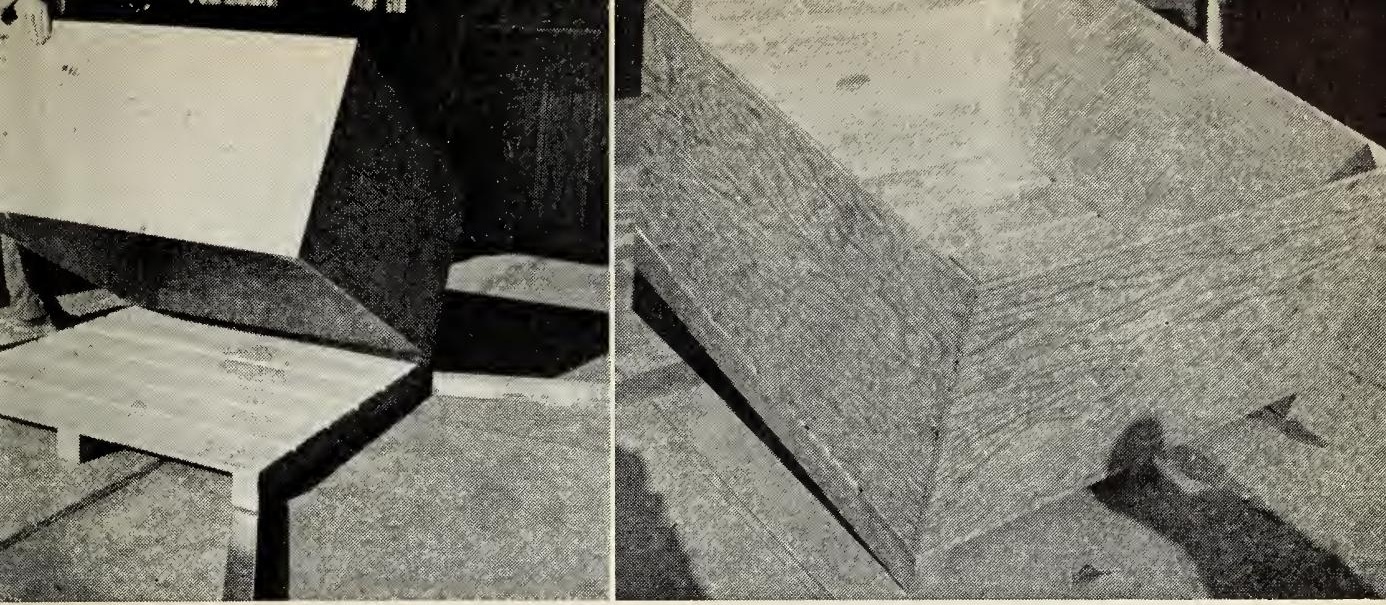

Above, left: Bin has three main parts, pallet, bin sides, and sheet-metal reinforcing. Pallet is made of six $1^{\prime \prime} \times 8^{\prime \prime} \times 47^{\prime \prime}$ construction-grade boards with 20-degree beveled edges. These are nailed to $3^{\prime \prime} \times 3 \frac{1}{2 \prime}{ }^{\prime \prime} \times 47^{\prime \prime}$ rough skids with $8 d$ galvanized nails.

Above, right: Bin body is made of four 23-15/16" $\times 46-3 / 8^{\prime \prime} \times 5 / 8^{\prime \prime}$ Exterior type $C$ (repaired) $C$ or $B C$ grade plywood sides fastened, with $8 d$ galvanized nails, to diagonally cut $4 \times 4^{\prime}$ s at corners. Sides are follow-around type and are all the same size. The $4 \times 4$, diagonally cut corners are $1 / 16^{\prime \prime}$ longer than the sides, to provide them some protection during stacking and handling.

Below: The 16-gauge, galvanized sheet-metal reinforcing corners are $2 \frac{1}{2}{ }^{\prime \prime}$ on each side, and extend from $1 / 4^{\prime \prime}$ below bin top to $1 / 4^{\prime \prime}$ above skid bottom. Holes are prepunched. These corners hold bin body to pallet. Galvanized nails are used; $8 \mathrm{~d}$ size is ample since they are subjected to shear and compression forces. The 18-gauge, galvanized sheet-metal caps on top of pallet entry sides of bin are held in place by an $8 \mathrm{~d}$ galvanized nail in each end, driven into the corner post at a slight angle.

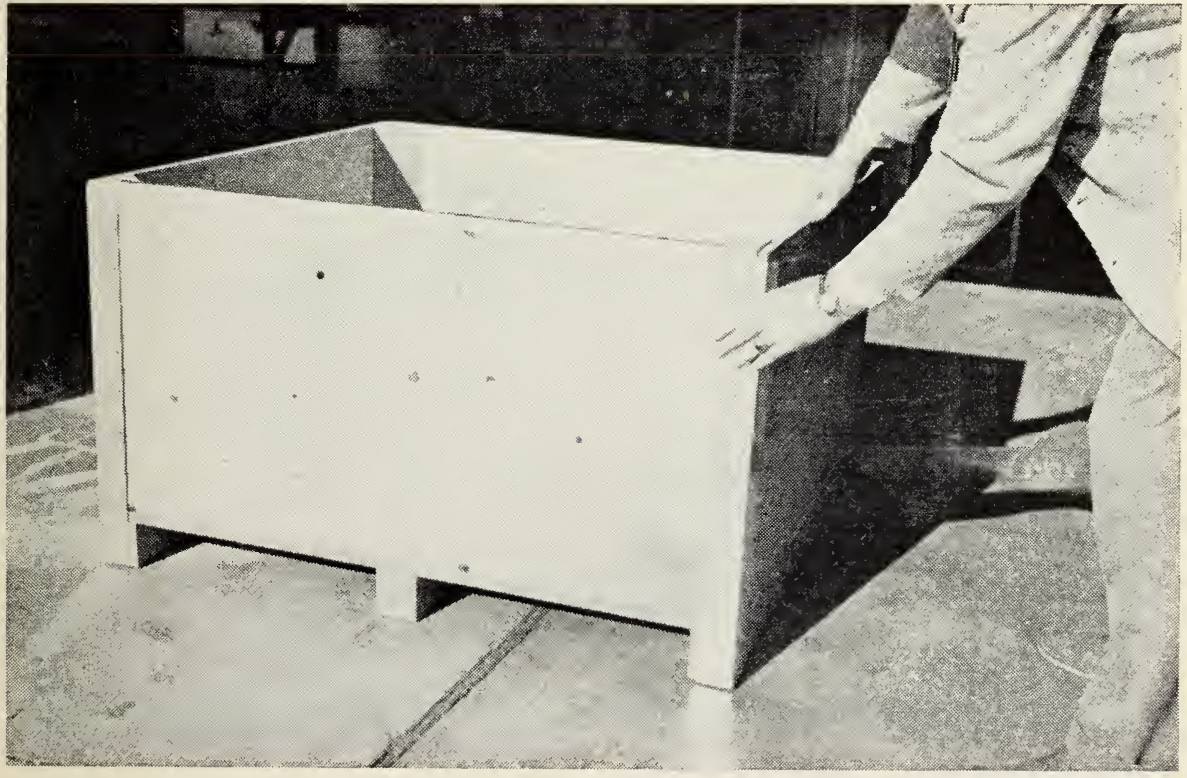




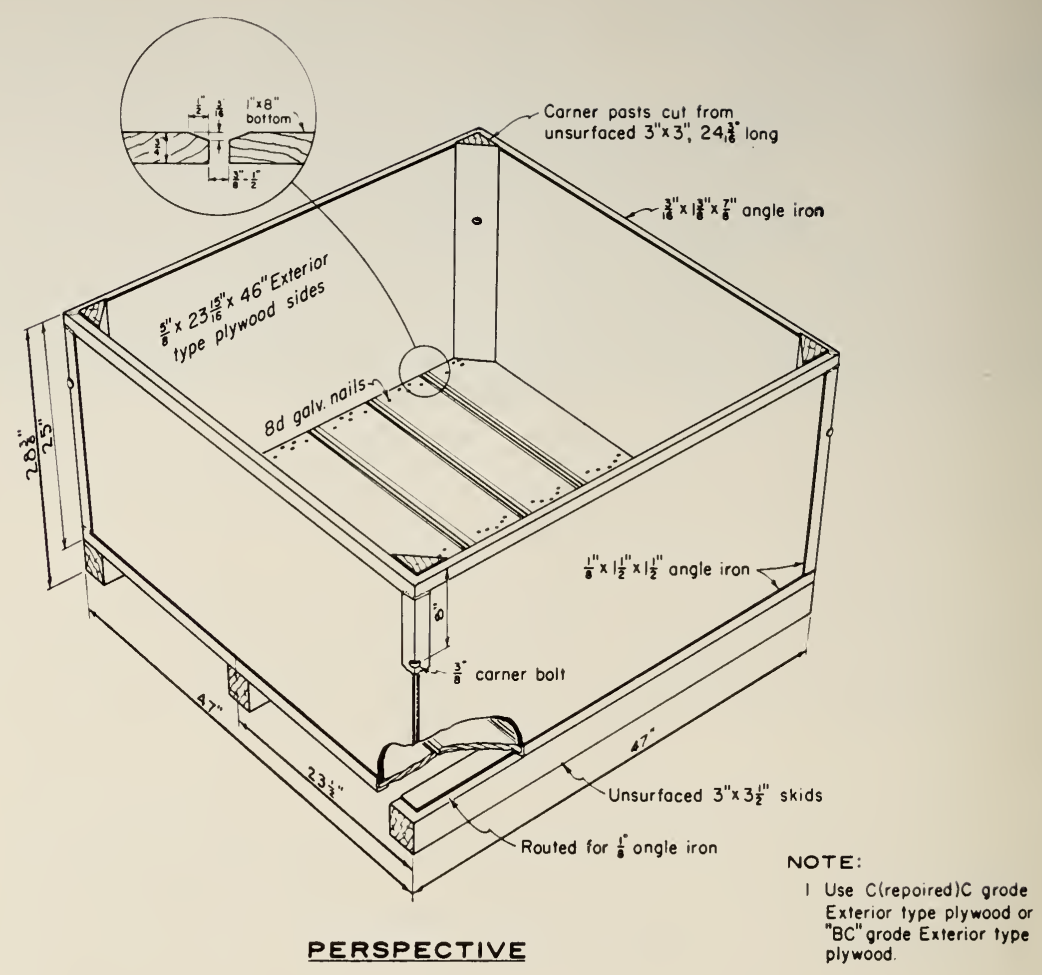

Detailed plan of angle iron-frame fruit bin. Wear-resistant features of this bin make it adaptable for short hauls and frequent use.

strength, and wear, and to ensure rigid altachment of bin to pallet.

Use 18-gauge, galvanized sheet-metal caps on tops of the two sides of the bin where forks may slide.

To prevent splitting or breaking, fasten metal reinforcing away from wood edges.

The insides of bins should be smooth to minimize abrasion damage to fruit. Any plywood used should be Exterior type. ("C repaired C" or "BC" grade plywood is adequate.)

Use corner posts of diagonally cut 4 by 4's for inside framing of side panels to obtain maximum bin capacity, stack. ing support, and adequate bearing surface to facilitate stacking.

Use dried lumber. Six $1 \times 8$-inch "construction and better" grade lumber with 20-degree eased edges are suitable for bottom boards. Allow about $3 / 8$-inch cracks in the bottom at the time of manufacture. Lumber shrinkage will widen the cracks to $1 / 2$-inch. The bottom boards should extend under the sides.

Allow for about 100 square inches of open space in the bottom of the bin to provide adequate ventilation for good cooling and storage conditions. 

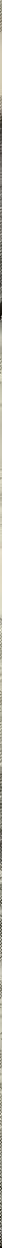

\section{REPAIRING BINS}

Repair holes in sides of bins by fastening a 26-gauge, galvanized sheet-metal patch over the hole. In this way the whole side need not be replaced.

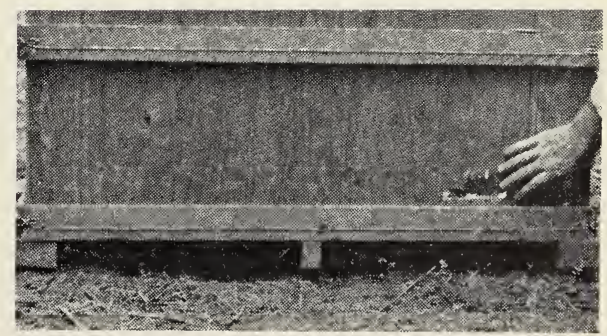




\section{Economy-type bin ...}

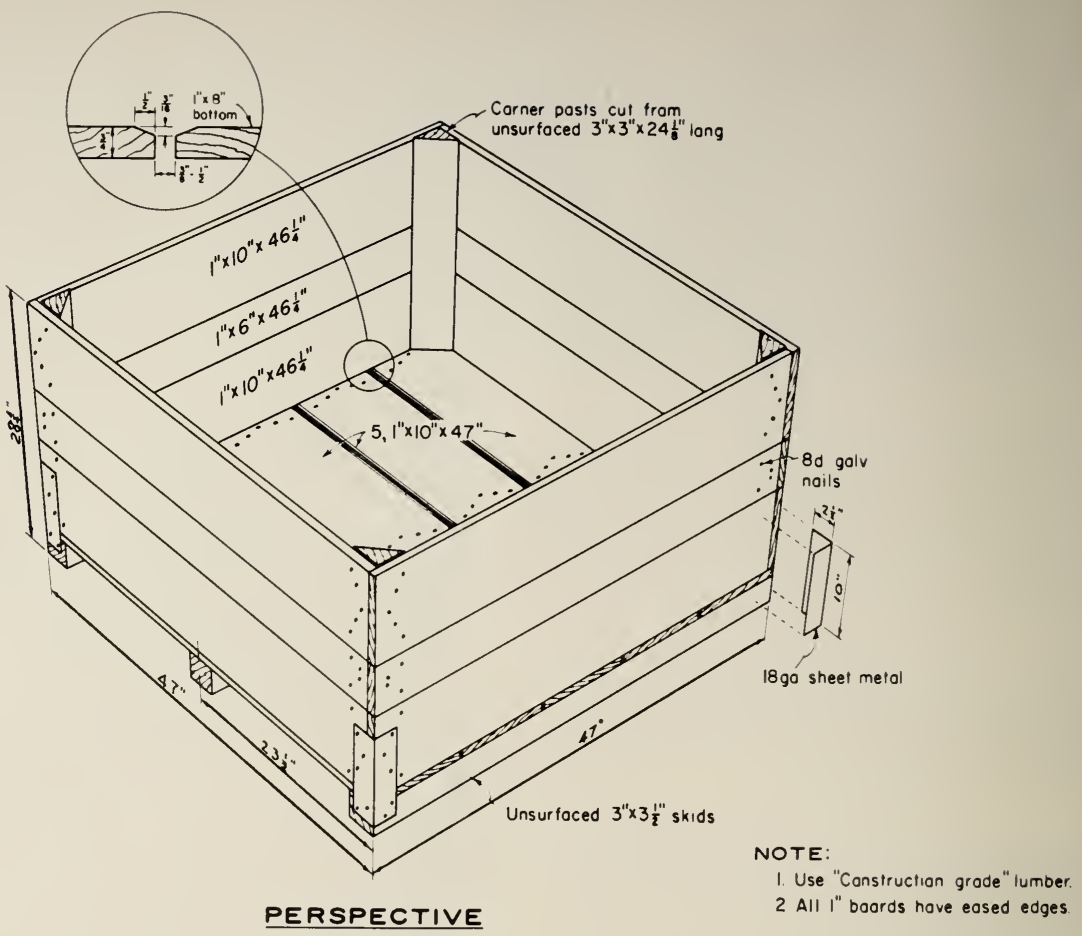

Plans for economy-type lumber fruit bin.

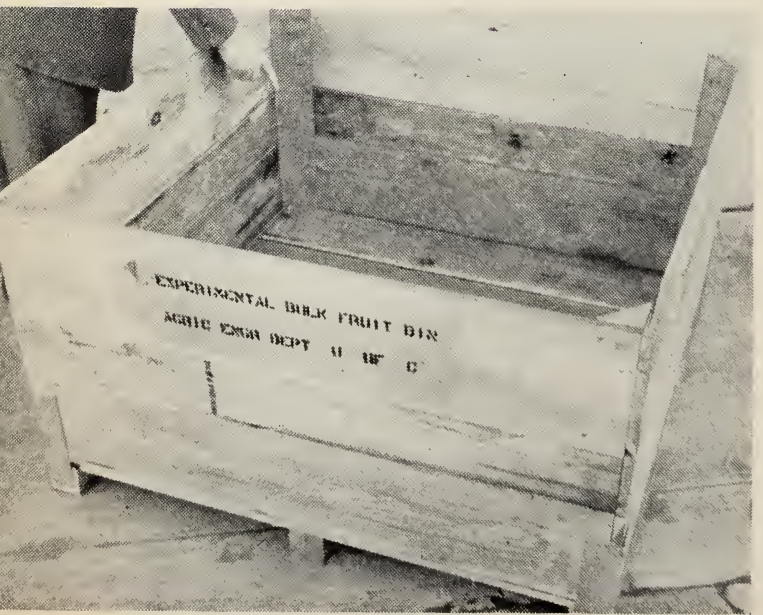

Economy bin is made of construction-grade lumber attached at the corners to diagonally cut $3^{\prime \prime} \times 3^{\prime \prime}$. Bin sides are attached to pallet by 18-gauge, galvanized sheet-metal angles. As shown in plan, adequate nailing is essential to rigidity.

Co-operative Extension work in Agriculture and Ilome Economics, College of Agriculture, University of California, and United States Department of Agrieulture co.operating. Distributed in furlherance of the Acts of Coniress of May 8, and June 30, 1914. George B. Alcorn. Director, California Asricultural Extension Service. 